\title{
CONTRIBUIÇÕES DE UMA LIGA ACADÊMICA PARA A FORMAÇÃO UNIVERSITÁRIA: REVISÃO DE LITERATURA
}

\section{Giulia Dos Santos Goulart'; Bárbara Belmonte Bedin²; Eduarda Hitter de Lima ${ }^{3}$; Gabrielli Billo Furtado ${ }^{3 ;}$ Mariana Ávila Monte ${ }^{3 ;}$ Patrícia Martins Fonseca ${ }^{3}$; Thais Chiarello Lopes ${ }^{3}$; Claudete Moreschi ${ }^{4}$}

\section{RESUMO}

Este estudo teve como objetivo identificar a produção científica existente acerca das contribuições de uma liga acadêmica para a formação universitária. Trata-se de uma Revisão Narrativa da Literatura, desenvolvida durante o mês de setembro de 2021, nas bases de dados Literatura Latino-americana e do Caribe em Ciências da Saúde, Sistema Online de Busca e Análise de Literatura Médica, Índice Bibliográfico Espanhol em Ciências da Saúde, Banco de Dados em Enfermagem - Bibliografia Brasileira, que foram acessadas via Portal Regional da Biblioteca Virtual em Saúde, utilizando a palavra-chave "Liga Acadêmica". Foram analisados 06 estudos, que emergiram as seguintes categorias: Colaboração para as experiências teóricopráticas na academia e Desenvolvimento pessoal e perspectivas profissionais dos ligantes. Percebe-se que as ligas acadêmicas são benéficas aos participantes, colaborando para as experiências teórico-práticas na academia, desenvolvimento pessoal e perspectivas profissionais dos ligantes, ampliando as competências e fornecendo conhecimento para futura atuação profissional dos universitários de forma qualificada.

Palavras-chave: Ensino; Extensão; Formação Acadêmica; Pesquisa.

Eixo Temático: Educação, Cultura e Comunicação (ECC)

\section{INTRODUÇÃO}

As Ligas Acadêmicas (LA) são entidades formadas por estudantes universitários, sob a orientação de um professor da instituição a qual está vinculada, podem ser interdisciplinar ou unidisciplinar, de acordo com o estatuto que a rege, tendo como intuito de vivenciar uma determinada temática integrando o tripé:

\footnotetext{
${ }^{1}$ Autora/Apresentadora - Universidade Regional Integrada do Alto Uruguai e das Missões - Campus Santiago. E-mail: giuliagoulart@outlook.com

${ }^{2}$ Coautora - Universidade Federal de Santa Maria.

${ }^{3}$ Coautora - Universidade Regional Integrada do Alto Uruguai e das Missões - Campus Santiago.

${ }^{4}$ Orientadora - Universidade Regional Integrada do Alto Uruguai e das Missões - Campus

Santiago.E-mail: clau-moreschi@yahoo.com.br
} 
Ensino, pesquisa e extensão. As organizações das LA são dirigidas pelos próprios acadêmicos o que demanda uma articulação interpessoal com os demais e o desenvolvimento de habilidades interpessoais e gerenciais durante a graduação (BENDELAQUE et al., 2019; SILVA et al., 2018).

Dessa forma, mediante a supervisão de docentes, os estudantes têm a possibilidade de desenvolver estudos científicos e aprofundar a sua base teórica em determinada área do conhecimento. Sendo possível, elaborar propostas para melhorar a saúde da comunidade local, consolidar o trabalho em equipe multiprofissional por intermédio da extensão universitária (SOARES et al., 2017).

Neste contexto, as LA oportunizam diferentes cenários de ensinoaprendizagem, interação entre os discentes e docentes, autonomia, respeito às diferenças, além da vivência multidisciplinar e interdisciplinar. Desenvolvendo atividades voltadas para a cidadania, sendo favorável tanto para os acadêmicos quanto a sociedade, por meio de atividades extracurriculares, desenvolvendo as ações no âmbito do ensino e pesquisa, auxiliando o acadêmico na sua formação profissional (CARVALHO et al., 2019).

Diante do cenário da educação brasileira, é fundamental a busca de novas estratégias para formação do aluno no ensino superior, de modo a ofertar conhecimento necessário para a sua futura atuação profissional e que sejam capazes de responder a complexas exigências e constantes desafios que promovem a articulação dos saberes, em vista disso as LA tem sido uma estratégia empregada pelas instituições de ensino superior (SILVA et al., 2020).

As instituições de ensino superior são capazes de exercer grande influência sobre a sociedade, além de ter relevância nos processos de modernização e melhoria da sociedade. A educação superior é uma grande geradora de influências sobre a sociedade, pois assume papel primordial no processo de evolução coletiva. Dessa maneira, as LA, surgem para aprimorar o ensino universitário e a aplicação do conhecimento teórico-prático (QUEIROZ et al., 2020).

Assim, esse trabalho foi conduzido pela seguinte questão norteadora: quais as contribuições de uma liga acadêmica para a formação universitária? E tem como 
objetivo, identificar a produção científica existente acerca das contribuições de uma liga acadêmica para a formação universitária.

\section{METODOLOGIA}

A Revisão Narrativa da Literatura (RNL) configura-se em uma revisão bibliográfica, caracterizada por publicações amplas, que possibilita a aquisição e atualização de conhecimento sobre um determinado tema, sendo adequada para descrever e analisar o desenvolvimento de um determinado assunto, sob o ponto de vista contextual e teórico (LACERDA; COSTENARO, 2016).

A organização desta revisão narrativa se deu em seis etapas: identificação do tema, questão norteadora e do objetivo da pesquisa; estabelecimento da palavrachave e bases de dados, além dos critérios para inclusão e exclusão; definição das informações a serem extraídas e avaliação dos estudos incluídos; após, interpretação dos resultados e apresentação da revisão e síntese do conhecimento.

A pergunta para condução desta revisão, que se caracteriza como a primeira etapa da organização, foi: Quais as contribuições de uma liga acadêmica para a formação universitária? Para responder esta questão de pesquisa a seleção dos estudos foi realizada durante o mês de setembro de 2021 por meio das seguintes Bases: Literatura Latino-americana e do Caribe em Ciências da Saúde (LILACS), Sistema Online de Busca e Análise de Literatura Médica (MEDLINE), Índice Bibliográfico Espanhol em Ciências da Saúde (IBECS), Banco de Dados em Enfermagem - Bibliografia Brasileira (BDENF) que foram acessadas via Portal Regional da Biblioteca Virtual em Saúde (BVS).

$\mathrm{Na}$ segunda etapa foram definidos como critérios de inclusão: artigos disponíveis na íntegra nos últimos 5 anos, em idiomas português, inglês ou espanhol, publicados e indexados nas referidas bases de dados. Como critérios de exclusão: artigos completos não gratuitos, estudos que não respondessem à pergunta de revisão e os trabalhos sem resumo ou com resumo incompleto. Artigos duplicados foram considerados apenas uma vez.

A terceira e quarta etapas se constituíram da busca na base a partir da 
palavra-chave "Liga Acadêmica". Nestas etapas foram encontrados 273 artigos, dos quais realizou-se a leitura dos títulos e resumos e, na sequência, a leitura na íntegra dos artigos que apresentavam conteúdo concernente ao objetivo proposto. Ao final deste processo, o corpus deste estudo resultou em seis artigos. Foi criado um fluxograma com o detalhamento das etapas de pesquisa (Figura 1).

Figura 1 - Fluxograma com o detalhamento da pesquisa

Aplicados critérios de inclusăo e exclusâo

Quais as contribuiçōes de uma LA para a formaçăo universitaria?
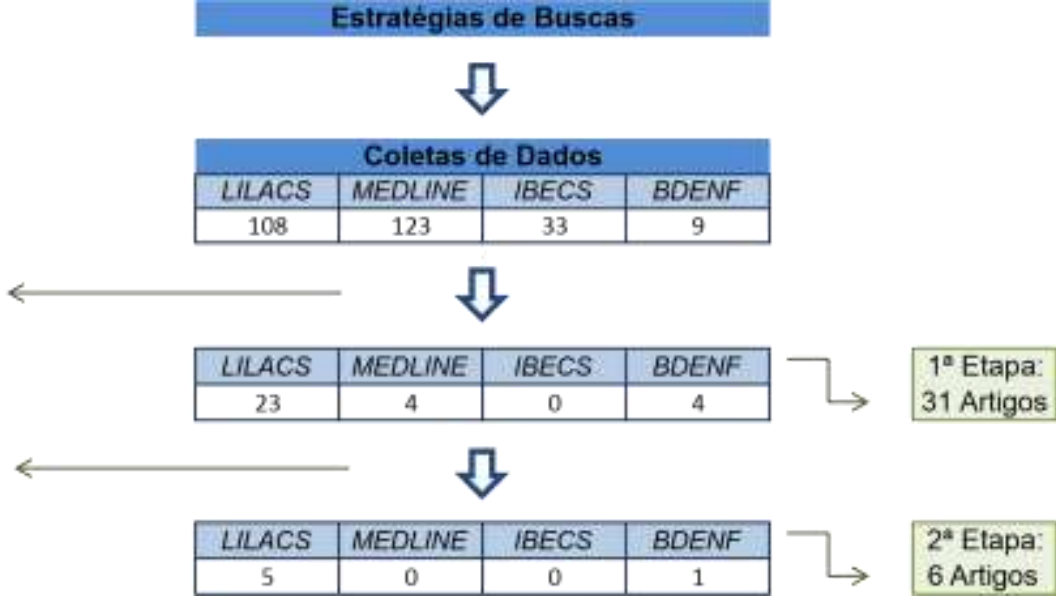

FONTE: Elaborado pelas autoras.

Posteriormente, as produções incluídas no corpus da revisão narrativa foram organizadas em um quadro sinóptico, sendo extraídas as seguintes variáveis: código, base de dados, periódico, autores), título, ano e objetivo. Como quinta etapa, ocorrereu a análise dos dados conforme a análise de conteúdo temática proposta por Minayo, que conta com três etapas: pré-análise, exploração do material e interpretação dos resultados (MINAYO, 2014); e, na sexta etapa, delinearam-se as considerações finais.

\section{RESULTADOS E DISCUSSÕES}

$\mathrm{Na}$ presente RNL, analisaram-se 06 estudos, que contemplaram a questão norteadora e os critérios de inclusão. Os mesmos foram analisados na íntegra para que a caracterização, interpretação e discussão fossem realizadas. Inicialmente 
foram apresentado os estudos selecionados, por meio do Quadro Sinóptico (Quadro

1), após foram descritos os principais resultados por meio de categorias temáticas.

Quadro 1 - Quadro Sinóptico de Produções incluídas no corpus da revisão narrativa

\begin{tabular}{|c|c|c|c|c|c|c|c|}
\hline NE & $\begin{array}{l}\text { Base do } \\
\text { dados }\end{array}$ & Autores & Titulo & Periódico & Ano & Objetivo & $\begin{array}{l}\text { Tipo de } \\
\text { Pesquisa }\end{array}$ \\
\hline 01 & LILACS & $\begin{array}{c}\text { PURIFICACAXO, } \\
\text { T. S: GALRAO, } \\
\text { H.A.S; KHOURI, } \\
\text { J. G. } \\
\text { R.; SANTOS, } \\
\text { J.D.N.; } \\
\text { CASTELAR, M. }\end{array}$ & $\begin{array}{l}\text { A construçâo de } \\
\text { um LARR: } \\
\text { contaçbes sobre } \\
\text { a criaça da } \\
\text { Liga Academica } \\
\text { de Relaçoes } \\
\text { Raciais. }\end{array}$ & $\begin{array}{l}\text { Rev. Psicol. } \\
\text { Divers. } \\
\text { Saúde }\end{array}$ & 2020 & $\begin{array}{c}\text { O presente artigo tem o } \\
\text { objetivo de relatara a } \\
\text { experiencia de criaçăo } \\
\text { da Liga Académica } \\
\text { de Relaçós } \\
\text { Raciais na Escola Bahia } \\
\text { na de Medicina e Saúde } \\
\text { Pública, } \\
\text { uma instituiçăo de ensin } \\
\text { o da cidade de } \\
\text { Salvador, Bahia. }\end{array}$ & Qualitativa \\
\hline 02 & LILACS & $\begin{array}{c}\text { VIEIRA, C. } \\
\text { B. SILVA, D. A. }\end{array}$ & $\begin{array}{c}\text { Contribuiçøes } \\
\text { de uma liga } \\
\text { académica do } \\
\text { trauma e } \\
\text { emergencia na } \\
\text { formaçao } \\
\text { universitaria: } \\
\text { percepça dos } \\
\text { integrantes }\end{array}$ & $\begin{array}{l}\text { Nursing (Säo } \\
\text { Paulo) }\end{array}$ & 2019 & $\begin{array}{l}\text { Este estudo teve por } \\
\text { objetivo compreender } \\
\text { a autopercepça dos est } \\
\text { udantes em relaçăo a } \\
\text { liga académica } \\
\text { do trauma e emergéncia } \\
\text { como estrategia que } \\
\text { direcione, capacite e } \\
\text { promova } \\
\text { o conhecimento e a } \\
\text { experiência. }\end{array}$ & Qualitativa \\
\hline 03 & LILACS & $\begin{array}{c}\text { YANG, G. Y: } \\
\text { BRAGA A. C. } \\
\text { B. HIPOLITO, } \\
\text { N. C. } \\
\text { VIEIRA, K. S. } \\
\text { T. } \\
\text { PESSANHA, } \\
\text { C.G: } \\
\text { ABRANTES, F. } \\
\text { G.; PEREIRA, } \\
\text { P.S. CORREA, } \\
\text { C.L. }\end{array}$ & $\begin{array}{c}\text { Liga de } \\
\text { Anatomia } \\
\text { Aplicada (LAA): } \\
\text { as Múltiplas } \\
\text { Perspectivas } \\
\text { sobre Participar } \\
\text { de uma Liga } \\
\text { Académica }\end{array}$ & $\begin{array}{l}\text { Rev. bras. } \\
\text { educ. méd: }\end{array}$ & 2019 & $\begin{array}{c}\text { Relatar a experiéncia de } \\
\text { participaçăo na Liga de } \\
\text { Anatomia Aplicada, com } \\
\text { base em multiplas } \\
\text { visós (orientadores, } \\
\text { diretores e público-alvo) } \\
\text { no periodo de } 2012 \text { a } \\
2017 \text {, a fim de obter } \\
\text { um feedback de açoes } \\
\text { passadas, } \\
\text { compreendendo os } \\
\text { erros e enfatizando os } \\
\text { acertos, e criar uma } \\
\text { fonte de referencia } \\
\text { futura para novas } \\
\text { gestobs a outras ligas } \\
\text { que venham a ser } \\
\text { fundadas, promovendo } \\
\text { a transmissło de } \\
\text { valores. }\end{array}$ & $\begin{array}{l}\text { Relato de } \\
\text { Experiencia }\end{array}$ \\
\hline 04 & LILACS & $\begin{array}{c}\text { MELO, T, } \\
\text { S: BERRY, M. } \\
\text { C: SOUZA, M. } \\
\text { I. }\end{array}$ & $\begin{array}{l}\text { Ligas } \\
\text { académicas de } \\
\text { Odontologia: } \\
\text { uma revisăo de } \\
\text { literatura }\end{array}$ & $\begin{array}{l}\text { Rev. } \\
\text { ABENO }\end{array}$ & 2019 & $\begin{array}{c}\text { O presente estudo tem } \\
\text { por objetivo buscar } \\
\text { na literatura subsidios p } \\
\text { ara delinear a } \\
\text { importância e } \\
\text { contribuiçalo } \\
\text { das ligas académicas } \\
\text { para a formaçalo dos } \\
\text { discentes } \\
\text { em Odontologia. }\end{array}$ & $\begin{array}{l}\text { Revisào de } \\
\text { Literatura }\end{array}$ \\
\hline
\end{tabular}




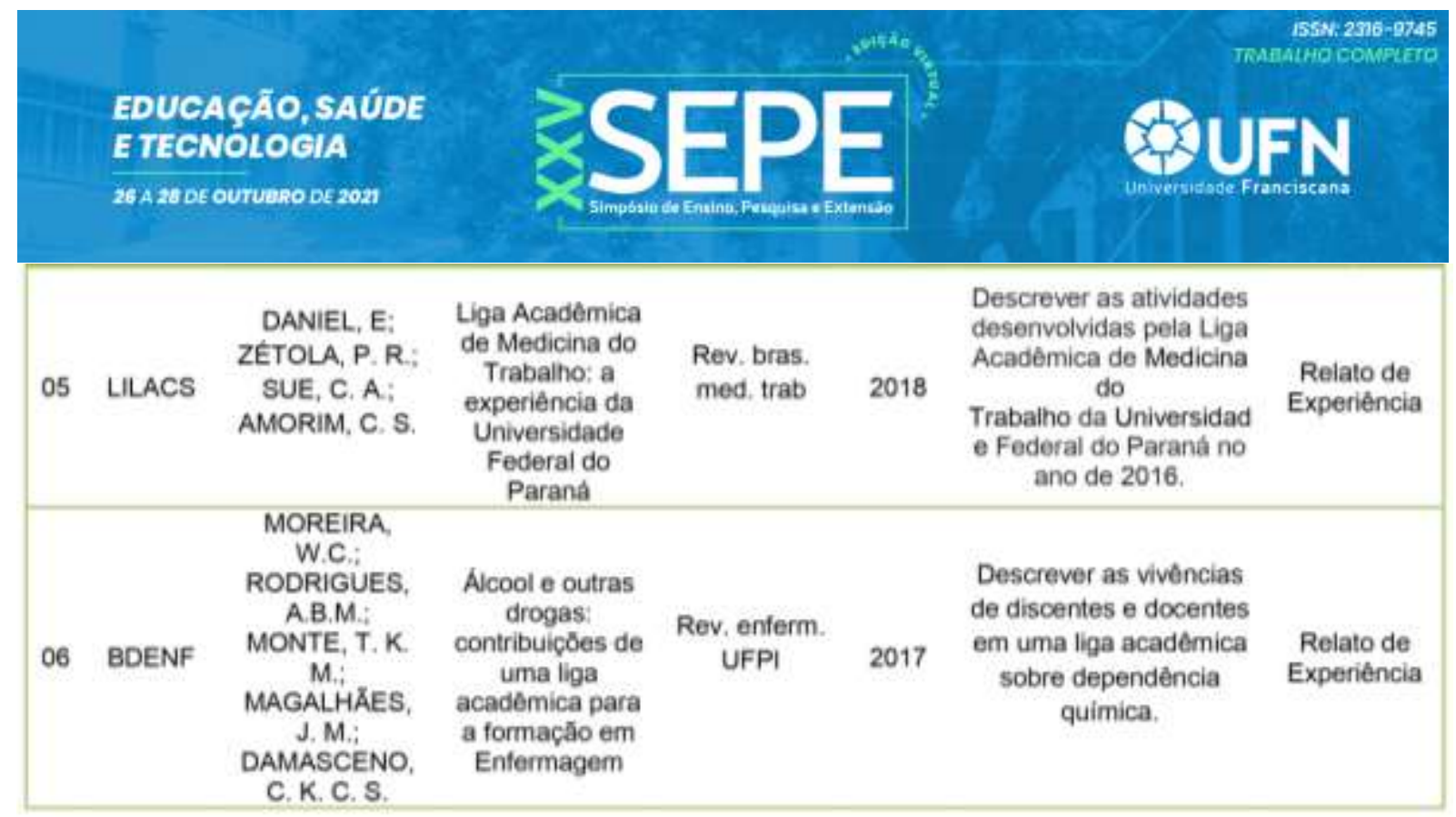

\subsection{Descrição dos estudos}

A evolução temporal dos artigos selecionados demonstrou que a publicação ocorreu gradativamente entre os anos de 2017 e 2020. Os seis artigos analisados foram publicados em periódicos diferentes não ocorrendo repetição. Em relação aos países de publicação, todos ps trabalhos (100\%) foram divulgados no Brasil. Três artigos (50\%) estudados tiveram como abordagem o relato de experiência, dois $(33,33 \%)$ tiveram metodologia qualitativa e um (16,67\%) caracterizou-se como revisão de literatura.

Quanto ao contexto abordado nos estudos, cinco estiveram relacionados ao aprimoramento dos conhecimentos teóricos e práticos dos acadêmicos, gerando novas experiências; dois à questão crítica, reflexiva e de liderança e dois ao crescimento pessoal dos ligantes. Assim, após a análise dos dados emergiram as seguintes categorias: Colaboração para as experiências teórico-práticas na academia e Desenvolvimento pessoal e perspectivas profissionais dos ligantes.

\subsection{Colaboração para as experiências teórico-práticas na academia}

Ligas acadêmicas possuem como finalidade a capacitação dos estudantes. A partir do seu caráter extensionista extracurricular, uma LA possibilita que o tripé de ensino, pesquisa e extensão seja compreendido, vivenciado e aprimorado pelos alunos. Isto gera crescimento, auxilia no crescimento do olhar profissional e contribui 
para que o acadêmico vivencie a humanização do cuidado desde o princípio da graduação e atinja qualidade em sua vida profissional (DANIEL et al., 2018; MOREIRA et al., 2017).

A participação em projeto de extensão possibilita o diálogo entre acadêmicos e comunidade, seja por meio de rodas de conversas e eventos ou por meio da escuta dos residentes e trabalhadores locais, o que facilita a compreensão profissional das necessidades sociais locais e enriquece as vivências culturais de ambos. (DANIEL et al., 2018; MELO; BERRY; SOUZA, 2019; MOREIRA et al., 2017; VIEIRA; SILVA, 2019; YANG et al., 2019).

A partir da oferta acadêmica de um espaço para aprofundar o conhecimento teórico-prático com reflexões e análises de informações relacionadas à prática, surge uma oportunidade de adquirir aprendizado, experiência e de estudar de forma dinâmica. O que contribui para o desenvolvimento de raciocínio clínico-científico, ampliação do conhecimento e desperta o interesse pela busca de assuntos diferentes aos da grade curricular (MOREIRA et al., 2017; YANG et al, 2019).

No que tange a área da saúde, as ligas têm papel fundamental na organização de práticas de promocão, prevenção e recuperação em saúde junto à comunidade. Isto pode ser feito por meio de grupos com usuários e trabalhadores locais, a partir de projetos de pesquisa que derivem da LA, ou até mesmo em conjunto com alguma disciplina da graduação. Tais práticas possibilitam o amadurecimento profissional. (MELO; BERRY; SOUZA, 2019; VIEIRA; SILVA, 2019)

Assim, do ponto de vista teórico-prático, as LA possibilitam o contato precoce com usuários, permitindo uma sensação de segurança na prática e em vivências clínicas e sociais com profissionais da área, o que gera um benefício para o aprendizado, pois desta forma as ligas acadêmicas surgem como instrumento para auxiliar no explorar do pensamento crítico, criativo e de autogestão (VIEIRA; SILVA, 2019; YANG et al., 2019).

\subsection{Desenvolvimento pessoal e perspectivas profissionais dos ligantes}


Participar de uma LA oferta tanto possibilidades assistenciais como de gestão. Isto estimula o desenvolvimento de um perfil de empreendedorismo social, liderança e auxilia na organização. Tal possibilidade gera contato com habilidades administrativas dos estudantes, seja em organização de eventos, em produções científicas, no contato interpessoal ou trabalho em equipe (YANG et al., 2019).

As atividades realizadas pelos estudantes na LA, favorece o desenvolvimento pessoal e profissional, mobiliza as capacidades de autonomia, comunicação e tomada de decisão, encontrando oportunidade de exercício da prática profissional. 0 desenvolvimento de competências é importante para que os discentes aprimorem sua criatividade diante da construção de soluções para determinados problemas (PURIFICAÇÃO et al., 2020; CAVALCANTE et al., 2021).

As ações extensionistas desenvolvidas pelos estudantes na liga, amplia as possibilidades de desenvolvimento, despertando a adoção de uma visão críticoreflexiva e social. Assim, as LA como estratégia de aproximação da prática com articulação do ensino e da pesquisa instigam o estudante a refletir. Neste contexto, as experiências vivenciadas nos diferentes níveis de atenção à saúde contribui na formação pessoal e profissional dos universitários e estabelece benefícios para a população (VIEIRA; SILVA, 2019; CARVALHO et al., 2021).

Os resultados que a liga produz aos universitários, refere-se ao auxílio no aprendizado do ligante, que futuramente se tornará um profissional, ocasionando influência para formar grandes profissionais, com subsídios para desenvolver-se pessoalmente e profissionalmente. Além de ampliar o currículo e as experiências do futuro profissional que está inserido na liga acadêmica, vivenciando a prática e a teoria em todas as etapas da aprendizagem na graduação (HENRIQUES et al., 2020).

Outro fator de grande destaque para os ligantes é o amadurecimento e o conhecimento adquirido através do trabalho realizado de forma eficaz, por fim as LA potencializam a prevalência da disseminação do conhecimento adquirido pelo acadêmico, gerando ações que proporcionam melhorias, utilizando o conhecimento em prol da formação (DANTAS; SANTOS; GOIS, 2017). 


\section{QUFN}

\section{CONCLUSÃO}

Em suma, observou-se que as ligas acadêmicas são benéficas para os participantes, aperfeiçoando a prática de autoaprendizado, liderança, inter-relação, empatia, aquisição de novas experiências e a troca mútua de conhecimento entre seus participantes e sociedade. Dessa forma, colaborando para as experiências teórico-práticas na academia, desenvolvimento pessoal e perspectivas profissionais dos ligantes, ampliando as competências e fornecendo conhecimento para futura atuação profissional dos universitários de forma qualificada. 


\section{REFERÊNCIAS}

BENDELAQUE, D. F. R. et al. Contribuição da liga acadêmica na formação e produção de conhecimento em saúde do idoso. Brazilian Journal of Health Review, v. 2, n. 4, p. 3774-3781, 2019.

CARVALHO, C. R. et al. Contribuição das ligas acadêmicas para Formação em enfermagem. Enfermagem em Foco, v. 10, n. 6, 2019.

CARVALHO, C. R. et al. Ligas acadêmicas e extensão universitária: contribuições na aprendizagem do estudante de enfermagem. Rev. Gestão e Saúde (Brasília). v. 12 n. 01 , p. $108-118,2021$.

CAVALCANTE, Ana Suelen Pedroza et al. Em busca da definição contemporânea de "ligas acadêmicas" baseada na experiência das ciências da saúde. InterfaceComunicação, Saúde, Educação, v. 25, p. e190857, 2021.

DANIEL, E. et al. Liga acadêmica de medicina do trabalho: a experiência da Universidade Federal do Paraná. Revista Brasileira de Medicina do Trabalho, v. 16, n. 2, p. 199-203, 2018.

DANTAS, A. C.; SANTOS, M. A.; GOIS, M. B. T. C. Importância da Liga Acadêmica para a formação profissional: aprendendo a trabalhar em equipe. In: Congresso Internacional de Enfermagem. 2017.

Enfermagem e Saúde: da teoria à prática. 1. ed. Porto Alegre: Moriá, 2016.

HENRIQUES, K. G. G. et al. Liga acadêmica em saúde da mulher e obstetrícia no processo de formação do enfermeiro. Brazilian Journal of Development, v. 6, n. 11 , p. 92335-92342, 2020.

\section{LACERDA M.R.; COSTENARO R.G.S. Metodologias da pesquisa para}

MELO, T. S.; BERRY, M. C.; SOUZA, M. I. Ligas acadêmicas de Odontologia: uma revisão de literatura. Revista da ABENO, v. 19, n. 1, p. 10-19, 2019. 
MINAYO, M.C.S. O Desafio do Conhecimento: pesquisa qualitativa em saúde. 14. ed. São Paulo: Hucitec, Abrasco, 2014.

MOREIRA, W. C. et al. Álcool e outras drogas: contribuições de uma liga acadêmica para a formação em Enfermagem. Rev. enferm. UFPI, p. 83-88, 2017.

PURIFICAÇÃO, T. S. et al. A construção de um LARR: contações sobre a criação da Liga Acadêmica de Relações Raciais. Revista Psicologia, Diversidade e Saúde, v. 9 , n. 4, p. 433-441, 2020.

QUEIROZ, G. V. R. et al. A influência da liga acadêmica como ferramenta na formação em saúde: um relato de experiência. Brazilian Journal of Development, v. 6, n. 6 , p. 40159-40203, 2020.

SILVA, D. A. et al. Educação em enfermagem: criação de uma liga acadêmica para o ensino de urgência e emergência. Research, Society and Development, v. 9, n. 3, p. e159932656-e159932656, 2020.

SILVA, D. P. et al. Proposição, fundação, implantação e consolidação de uma liga acadêmica. Rev. enferm. UFPE on line, p. 1486-1492, 2018.

SOARES, L. R. et al. Iniciação científica na graduação: experiência da Liga da Mama da Universidade Federal de Goiás. Rev Bras Mastologia, v. 27, n. 1, p. 21-5, 2017.

VIEIRA, C. B.; DA SILVA, D. A. Contribuições de uma liga acadêmica do trauma e emergência na formação universitária: percepção dos integrantes. Nursing (São Paulo), v. 22, n. 259, p. 3383-3387, 2019.

YANG, G. Y. et al. Liga de Anatomia Aplicada (LAA): as Múltiplas Perspectivas sobre Participar de uma Liga Acadêmica. Revista Brasileira de Educação Médica, v. 43, p. 80-86, 2019. 